\title{
Use of Ceramic Waste as Fine Aggregate in Bituminous Mix in Flexible Pavement Design
}

\author{
Md. Murad Hasan 1, *, Mehejabin Chowdhury Ankan², Md. Ebrahim Shaik ${ }^{3}$, Md. Rasel Ali ${ }^{4}$ \\ ${ }^{1}$ Western Bangladesh Bridge Improvement Project (WBBIP), Oriental Consultant Global Limited, Jashore, Bangladesh \\ ${ }^{2}$ Western Bangladesh Bridge Improvement Project (WBBIP), Jashore, Bangladesh \\ ${ }^{3}$ Department of Civil Engineering, Northern University of Business \& Technology, Khulna, Bangladesh \\ ${ }^{4}$ Department of Civil Engineering, Rajshahi University of Engineering and Technology, Rajshahi, Bangladesh
}

Email address:

muradhasan.ce@gmail.com (Md. M. Hasan),mehjabinankan@gmail.com (M. C. Ankan), ebrahimkuet82@gmail.com (Md. E. Shaik), raselalice140042@gmail.com (Md. R. Ali)

*Corresponding author

\section{To cite this article:}

Md. Murad Hasan, Mehejabin Chowdhury Ankan, Md. Ebrahim Shaik, Md. Rasel Ali. Use of Ceramic Waste as Fine Aggregate in Bituminous Mix in Flexible Pavement Design. Landscape Architecture and Regional Planning. Vol. 5, No. 2, 2020, pp. $33-37$. doi: $10.11648 /$ j.larp.20200502.13

Received: December 2, 2019; Accepted: December 16, 2019; Published: June 3, 2020

\begin{abstract}
In bituminous road construction aggregate is the principal material. Aggregates constitute about $90 \%$ or even more of the total construction materials. While selecting aggregate for road construction, search has to be intensified for easily accessible, low-cost natural aggregates and investigate the suitability of indigenous aggregates. Every effort must be taken to select the most economical aggregate which should also perform satisfactorily the design criteria for the road construction conditions. A laboratory investigation was carried out to investigate the design performance of bituminous pavement using different fine aggregates. While constructing bituminous pavement a mix of coarse aggregate, fine aggregate, mineral filler, and bitumen are used. The demand for natural fine aggregate can be reduced by recycling waste tiles chips. Waste tiles, chips aggregate refer to aggregate that has been previously used in the concrete structure as a floor finish. This study easy carried out to investigate the possibility of using waste tiles, chips as a fine aggregate. Therefore, two types of fine aggregate were used to study and compare the behavior of bituminous mixes using waste tiles with that of coarse sand. The Marshall Mix design procedure specified by AASHTO standard was followed in the determination of stability, flow, density, voids in the mixes and the optimum bitumen content. The test specimens were compacted with 50 blows from the consideration of medium traffic. The test results indicated that dense graded bituminous mixes with two types of different fine aggregates satisfy the Marshall Design criteria. From the economic consideration, mixes with waste tiles, chips are comparatively more suitable when available at the construction site. Dense bituminous mix using waste tiles, chips as fine aggregate for medium traffic, is a feasible option from the standpoint of stability, stiffness, deformations and void characteristics.
\end{abstract}

Keywords: Tiles, Bitumen, Fine Aggregate, Marshal Test, Pavement

\section{Introduction}

In this developmental time, using ceramic tiles is increasing day by day in houses. The main cause of this is that tiles are light in weight, easily maintainable and installation is easy. The most important things of increasing using tiles are it saves plastering cost, distempering cost, maintenance cost and at the same time looks like natural work. Its aesthetic view is beautiful. Anyone can install any kind of design easily. Typical raw materials normally used in a ceramic tile are clay, feldspar, pottery stone, silica sand, and talc.

Ceramic waste is replaced partially as a filler as well as aggregate in flexible pavement [1]. A bituminous concrete mixes with ceramic dust and hydrated lime were prepared in different proportions $(3 \%$ and $5 \%)$ as filler. The stability values and other parameters of samples containing ceramic wastes are improved in comparison to conventional mineral 
fillers [2]. Using Ceramic waste aggregate 5, 10, 15, 20\% replacement of natural aggregate in bituminous macadam pavement. Marshal stability, flow value and were determined by the replacement of ceramic aggregates and compare with the natural aggregates stability and flow value. It is observed that by replacing $5 \%, 10 \%, 15 \%$ natural aggregates with ceramic waste there is not the remarkable reduction in stability values [3].

Cagdas and Karacasu reported that a waste ceramic aggregate could replace, for binder course up to $30 \%$ and wearing course up to $20 \%$ presenting sufficient mechanical conditions [4]. A mixture which contains 30\% CW was lighter $(11 \%)$ than the conventional mixtures in equal volume. It means that trucks can carry HMA more than before. So in the context of the sustainable environment, using recycled waste ceramic aggregates in HMA prevents pollution.

Usually asphalt aggregates are used in pavement surface and these are occupied more than 50 percent surface area in urban zone. Generally dark asphalt layer do not have good enough reflectance property, \& it causes in raising temperature up to 48 to 67 degree Celsius, which contribute to build heat island effects [8]. Hot mix asphalt (HMA) is used in highway construction and it is known as an expensive item. Due to its high cost, the quantity of good quality material in the HMA is reduced, that demand the alternative source of material. There are lot of debris, construction waste, which are affecting the quality environment, came into to the researcher's concern to do recycled and reusing to prevent the pollution, as well as an alternative natural resources of pavement construction material [9]. In recent years, reusing and recycling of waste material is augmented in a great range aiming sustainable development and protect the environment from undesirable pollution [9]. The application of recycled waste material in bituminous mix design is settled down through numerous research works, where each type of waste considered for their individual characteristics [11].

Waste ceramic tiles as an alternative material to improve the performance of the CL-type soil in an economically and environmentally beneficial [5]. Chemical and mechanical properties of ceramic tiles debris permit their application as raw aggregate for reusing in pavement construction [10]. It is feasible to use finely crushed ceramic in the manufacture of paving blocks [6]. Water - cement ratio (0.46), core compressive strength increase by $3.9 \%$ to $5.6 \%$ by replacing $20 \%$ cement content with ceramic dust. It was observed that no significant change in flexural strength and split-tensile strength when compared to conventional concrete [7].

\section{Methodology}

A bituminous mixture is normally composed of aggregates and bitumen. The aggregates are generally divided into coarse, fine and mineral filler fractions according to the size of individual particles. A view of aggregate sites and ceramic wastes is shown in the following Figure 1.

Two types of mixes were studied and these were designed as mix type A and mix type B based on the type of fine aggregates used.

Mix A: black stone chips $(\mathrm{CA})+$ coarse sand $(\mathrm{FA})+$ stone dust (MF) + bitumen.

Mix B: black stone chips $(\mathrm{CA})+$ waste tiles $(\mathrm{FA})+$ stone dust (MF) + bitumen.

At the beginning, a typical aggregate gradation to give the most satisfactory behavior for bituminous macadam of $40 \mathrm{~mm}$ to $50 \mathrm{~mm}$ thickness, recommended by AASHTO, Hand Book2000 was selected for this study as presented in Table 1.

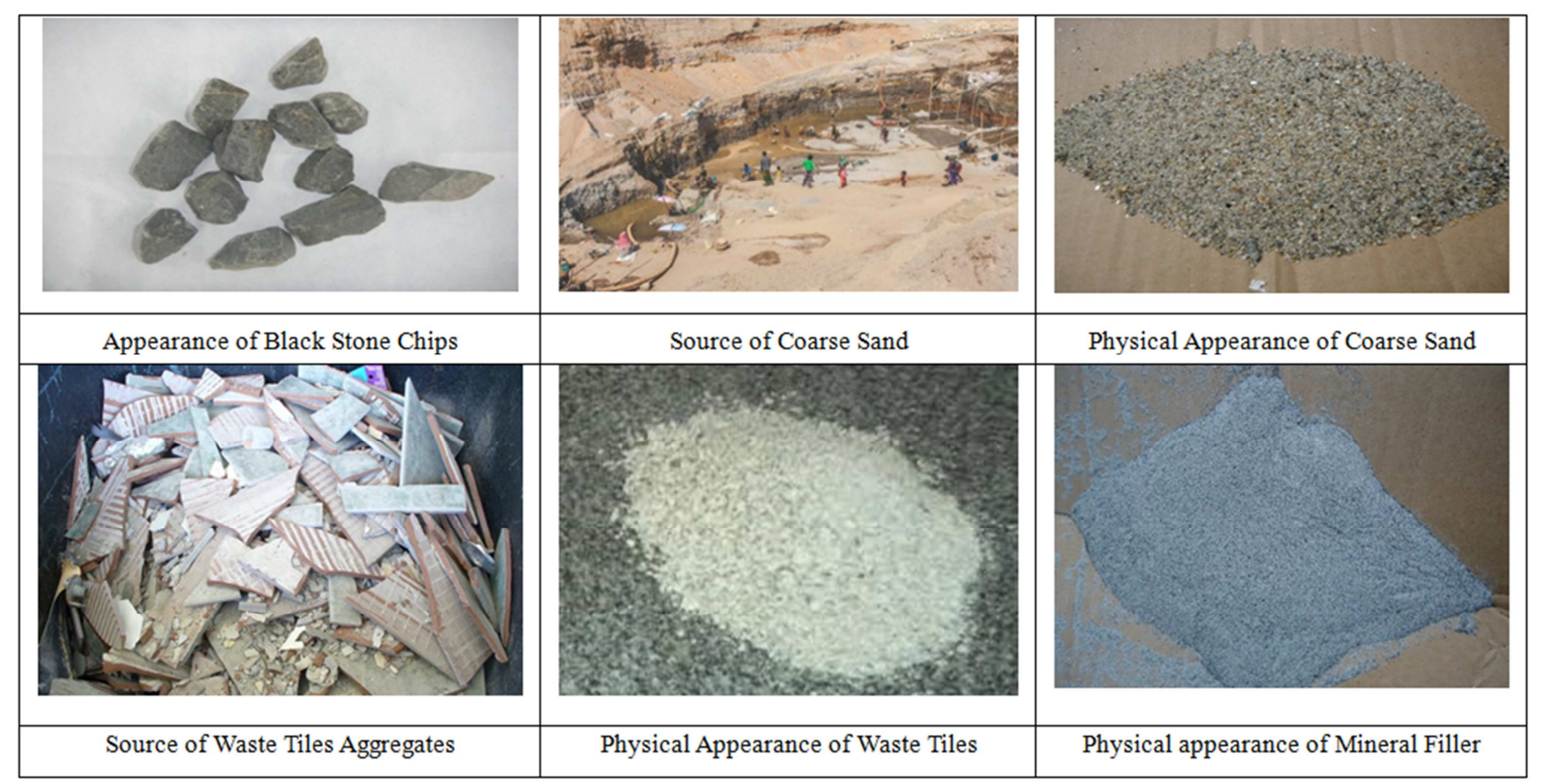

Figure 1. A view of aggregate sites and ceramic wastes. 
Table 1. Gradation Table of the Mix in the Mix.

\begin{tabular}{lll}
\hline \multirow{2}{*}{ Sieve size, $\mathbf{m m}$} & Percent by weight & Blend \\
\cline { 2 - 3 } & Specification & 0 \\
\hline 25 & 100 & 95 \\
19 & $90-100$ & 77 \\
12.5 & $70-85$ & 65 \\
9.5 & $55-75$ & 37 \\
4.75 & $35-40$ & 30 \\
2.36 & $25-35$ & 20 \\
1.18 & $15-25$ & 15 \\
0.6 & $10-20$ & 8 \\
0.3 & $6-10$ & 4 \\
0.075 & $0-8$ & 4 \\
\hline
\end{tabular}

To investigate the marshal stability of bituminous mixes with different aggregates 30 specimens of $101.6 \mathrm{~mm}$ diameter and approximately $63.5 \mathrm{~mm}$ thickness were prepared. The test procedure was introduced by Bruce Marshall and developed by the U.S. Corps of Engineers has been followed in the laboratory investigations.

Table 2. Properties of Fine aggregates.

\begin{tabular}{llll}
\hline S. N. & Properties & Fine Aggregates & Waste tiles \\
\cline { 3 - 4 } & & Coarse Sand & 1390 \\
\hline 1. & Loose unit wt. $\mathrm{Kg} / \mathrm{m}^{3}$ & 1440 & 1395 \\
2. & Dense unit wt. $\mathrm{Kg} / \mathrm{m}^{3}$ & 2.461 & 2.397 \\
3. & Bulk sp. Gravity & 2.647 & 2.525 \\
4. & Apparent sp. Gravity & 3.125 & 3.243 \\
5. & Water absorption, (\%) & \\
\hline
\end{tabular}

\section{Illustrations}

\subsection{Properties of Different Fine Aggregates}

The bulk specific gravity of Coarse sand and Tiles waste are 2.461 and 2.397 respectively. So the bulk specific gravity of coarse sand and tiles waste is almost the same. Test results of physical properties of different fine aggregates are summarized in Table 2.

The water absorption of coarse sand and tiles waste is $3.125 \%$ and $1.24 \%$ respectively. So the water absorption of tiles waste is less than the coarse sand due to low porosity than coarse sand.

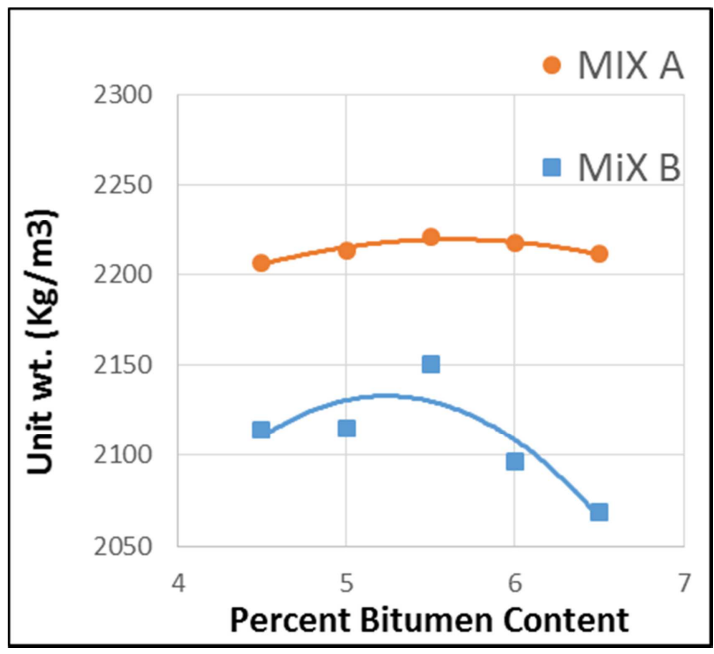

\subsection{Effect of Fine Aggregates on the Behaviour of Bituminous Mixes}

The optimum bitumen content for different mixes is determined from the Marshall Property curves by following the Marshall Mix design procedure. For each mix type, a set of 6 curves is drawn showing the relationships of unit weight, Marshall stability, flow value, percent air voids, percent voids in mineral aggregate, percent voids filled with bitumen with a percentage of bitumen content.

A close study of the tables and the figures reveal that there are similarities between the curves of bituminous mixes of waste aggregates and bituminous mixes of natural aggregates. All design graphs for Marshall Mix Design for Hot Mix Asphalt (HMA) are in the following Figure 2.

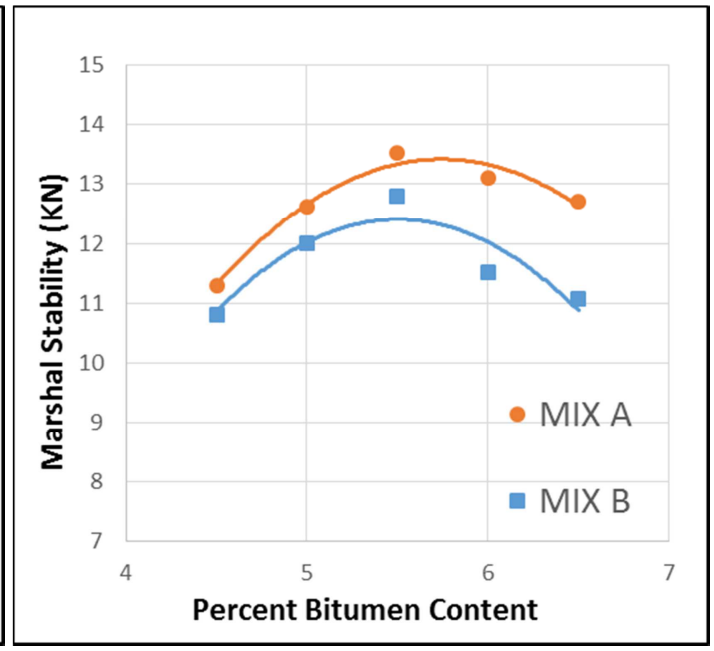



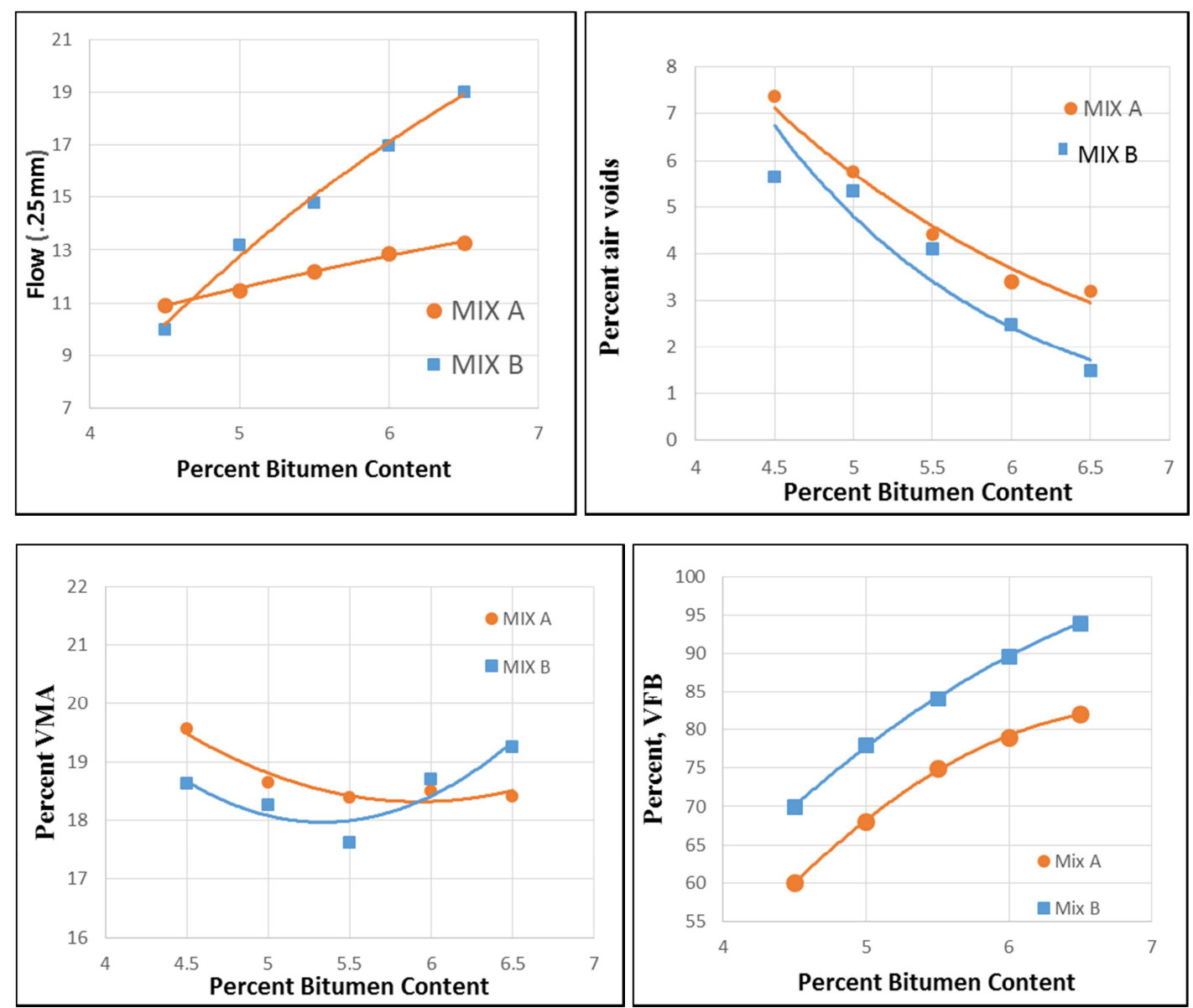

Figure 2. All design graphs for Marshall Mix Design for Hot Mix Asphalt (HMA).

At optimum bitumen content, the values of unit weight, Marshall Stability, flow, value percent of air voids in the total mix, percent of voids in mineral aggregates, percentage of voids filled with bitumen and Marshall Stiffness for mix type $\mathrm{A}$ and $\mathrm{B}$ are given in Table 3.

Table 3 shows the Marshall Stability at optimum bitumen content for mix types A and B 13 and $12.7 \mathrm{KN}$ respectively. These two Values satisfy the limiting value $(3.336 \mathrm{KN})$ specified by The Asphalt Institute as shown in Table 4. The flow values are 12.5 and 12.3 respectively. These values satisfy the limiting value 8-16 specified by the Asphalt Institute as shown in Table 4. From Table 3 it is found that in Optimum Bitumen content, $\% \mathrm{Va}$ for mix type $\mathrm{A}$ and $\mathrm{B}$ $4.1 \%$ and $3 \%$ respectively. These Values satisfy the limiting values 3-5\% specified by the Asphalt institute as shown in Table 4. Table 3 shows that at Optimum Bitumen content, \%VMA for mix type A and B 18.8 and 17.7 respectively. These Values satisfy the limiting values $12 \%$ specified by the Asphalt Institute as shown in Table 4. Table 3 shows that at Optimum Bitumen content, \%VFB for mix type A and B 76\% and 77\% respectively. These Values satisfied the limiting values $65 \%-78 \%$ specified by the Asphalt institute as shown in Table 4.

From Table 3, it is found that the stiffness value of Mix type A and B at optimum bitumen content are 4.16 and 4.22 $\mathrm{KN} / \mathrm{mm}$ respectively. All these values are above the required value of $2.1 \mathrm{KN} / \mathrm{mm}$. The stiffness value of mix with natural aggregate is nearly equal to that mixes with waste aggregate.

Bangladesh has a large network of industries and this produced a huge amount of wastes are produced in these establishments. Laboratory tests were performed for defining the physical properties of ceramic tiles and found to be within acceptable limits which show that ceramic tiles are feasible for use as a fine aggregate material in the bituminous mix in flexible pavement.

Table 3. Comparison of two types of aggregate.

\begin{tabular}{llllllllll}
\hline Mix Types & O. B. C & $\begin{array}{l}\text { Unit Weight } \\
\left(\mathbf{k g} / \mathbf{m}^{\mathbf{3}}\right)\end{array}$ & $\begin{array}{l}\text { Marshall } \\
\text { Stability }(\mathbf{K N})\end{array}$ & Flow (.25mm) & Air Voids (\%) & VMA (\%) & VFB (\%) & $\begin{array}{l}\text { Marshal stiffness } \\
(\mathbf{K N} / \mathbf{m m})\end{array}$ \\
\hline A & 5.65 & 2305 & 13 & 12.5 & 4.1 & 18.8 & 76 & 4.16 \\
B & 5.53 & 2130 & 12.7 & 12.3 & 3.0 & 17.7 & 77 & 4.22 \\
\hline
\end{tabular}


Table 4. Design Criteria for the Marshall Method.

\begin{tabular}{|c|c|c|c|c|c|c|}
\hline \multirow{2}{*}{ Marshall method mix Criteria } & \multicolumn{2}{|c|}{ Light traffic Surface \& Base } & \multicolumn{2}{|c|}{ Medium Traffic Surface \& Base } & \multicolumn{2}{|c|}{ Heavy Traffic Surface \& Base } \\
\hline & Min. Max. & & Min. & Max. & Min. & Max. \\
\hline Compaction (No. of blows each end) & 35 & & 50 & & 75 & \\
\hline Stability, N (Kg) & $3336(340)$ & & $5338(544)$ & & $8006(816)$ & \\
\hline Flow $(.25 \mathrm{~mm})$ & 8 & 18 & 8 & 16 & 8 & 14 \\
\hline \%Air Voids & 3 & 5 & 3 & 5 & 3 & 5 \\
\hline$\%$ VFB & 70 & 80 & 65 & 78 & 65 & 75 \\
\hline
\end{tabular}

\section{Conclusions}

Based on the experimental results of this study, the following conclusions are found:

Tiles waste chips are suitable as fine aggregates in bituminous mixes from the consideration of physical properties. Tiles waste chips as fine aggregate in bituminous mix satisfy the Marshall Mix design criteria. The Optimum Bitumen Content in mix with tiles waste is slightly lower than that of coarse sand due to their one surface is nickel coated. The bituminous mixes with tiles waste as fine aggregate give satisfactory results when they are constructed using dense grading, good compaction and optimum bitumen content for medium traffic.

\section{References}

[1] Vaghadia, B. K., Bhatt, M. R. (2016). A STUDY ON EFFECT OF WASTE CERAMIC TILES IN FLEXIBLE PAVEMENT. International Journal of Advanced Engineering and Research Development (IJAERD), 3 (10).

[2] Fatima, E., Sahu, S., Jhamb, A., and Kumar, R., (2014). Use of Ceramic Waste as Filler in Semi -Dense Bituminous Concrete. American Journal of Civil Engineering and Architecture, 2 (3).

[3] Jinal, V. P., Varia, H. R., Mishra, C. B. (2017). Design of Bituminous Mix with and without Partial Replacement of Waste Ceramic Tiles Material, International Journal of Engineering Research \& Technology (Ijert), 6 (4).
[4] Çağdaș, K., and Karacasu, M. (2015). Use of Ceramic Wastes in Road Pavement Design. Proceedings of the World Congress on New Technologies, Barcelona, Spain, Paper No. 226.

[5] Cabalar, A. F., Hassan, D. I., and Abdulnafaa, M. D. (2016). Use of waste ceramic tiles for road pavement subgrade. Road Materials and Pavement Design, 18 (4), 882-896.

[6] Dina, M., Sadek, H., Nouhy, A. E. (2013). Properties of paving units incorporating crushed ceramic. HBRC Journal, 10 (2), 198-205.

[7] Fatima, E., Jhamb, A., and Kumar, R. (2013). Ceramic Dust as Construction Material in Rigid Pavement. American Journal of Civil Engineering and Architecture, 1 (5), 112 -116.

[8] Anting, N., Din, M. F. M., Ponraj, M., Iwao, K., Chelliapan, S., \& Ubukata, N. (2014). Optimal mixture design of mix-wasted tile aggregates for reducing pavement surface temperature. Journal of Materials in Civil Engineering, 27 (9), 04014239.

[9] Kara, Ç., \& Karacasu, M. (2017). Investigation of waste ceramic tile additive in hot mix asphalt using fuzzy logic approach. Construction and Building Materials, 141, 598-607.

[10] Silvestre, R., Medel, E., García, A., \& Navas, J. (2013). Utilizing recycled ceramic aggregates obtained from tile industry in the design of open graded wearing course on both laboratory and in situ basis. Materials \& Design, 50, 471-478.

[11] Silvestre, R., Medel, E., García, A., \& Navas, J. (2013). Using ceramic wastes from tile industry as a partial substitute of natural aggregates in hot mix asphalt binder courses. Construction and Building Materials, 45, 115-122. 